\title{
Entrevista com Marta Maria do Amaral Azevedo realizada em 7 de abril de 2016
}

\author{
Maria Augusta Assirati
}

A demógrafa paulista Marta Maria do Amaral Azevedo foi a primeira mulher a presidir a Fundação Nacional do Índio, permanecendo à frente da instituição, de abril de 2012 até o início de junho de 2013. Formada em Ciências Sociais, afirma já ter ingressado na Universidade de São Paulo, onde concluiu o curso de graduação, decidida a trabalhar com povos indígenas. Relembra que naquele momento, ainda prevalecia no campo das ciências sociais, a visão de que os índios seriam extintos, integrados à sociedade dominante, a despeito do espírito de luta que marcava o papel da esquerda no cenário político da época. Enfatizando a importância do aumento da participação das lideranças indígenas, sobretudo jovens, nas decisões das questões que envolvem o segmento, acredita que os aliados desses Povos não devem ficar presos àquilo que acham, e sim, estar dispostos a aprender com os indígenas. Segundo Azevedo, ainda há no âmbito das políticas públicas, um pensamento que não leva em conta outras maneiras de viver e de ser feliz. "As políticas públicas universalizantes têm a vantagem da pretensão de alcançar todo mundo. Mas são massificantes, e é aí que são massacrantes para os povos indígenas.".

Quando e como começou a desenvolver atividades junto a povos indígenas?

Eu trabalhava e fazia faculdade ao mesmo tempo. Eu ficava de olho; tudo que era oportunidade que havia de trabalhar com índio, ir para aldeia, me candidatava. Surgiu, então, uma oportunidade de realizar um trabalho com os Guarani Kaiowá na região de Amambai, Mato Grosso do Sul, acompanhando um antropólogo que estava iniciando no Brasil, um projeto então chamado "desenvolvimento comunitário", que já vinha 
sendo feito com os Kaiowá do lado Paraguaio. Foi em 1977. Em julho de 1978 eu me mudei para lá, quando concluí o último semestre da faculdade.

O que a relação com comunidades indígenas significa para você? O que ela modificou em sua experiência de vida?

A relação com os indígenas logo transbordou os limites da relação acadêmica. Porque já entrei pela via de um projeto que não era um trabalho apenas de pesquisa. Era o que hoje se chama pesquisação. Naquele tempo, tinha uma linha que vinha da Antropologia Latino-americana e da Antropologia Aplicada francesa, com uma visão menos teórica e mais aplicada sobre o conhecimento antropológico e o "fazer do antropólogo". Era uma linha adotada por antropólogos mais ativistas. Eu entrei por aí. Logo me aproximei desses pessoas e grupos que estavam começando a trabalhar com esse compromisso com os povos indígenas, como a Manuela Carneiro da Cunha, Lux Vidal, Aracy Lopes da Silva, Dominique Gallois, o pessoal do Centro de Trabalho Indigenista, da Comissão Pró Índio do Acre, etc...Na relação com os índios a vida vira de ponta cabeça. Era o tempo inteiro a gente aprender. A gente aprende a língua, aprende a fazer fogo, aprende a ficar sem luz, com água só numa lata, a escovar os dentes com um copo de água... Eu acreditava que o sistema econômico, social que agente vivia estava falido, e que a gente tinha que achar outras saídas para além da saída política comunista, socialista, que era o pensamento de esquerda com o qual eu me identificava. Com os Guarani eu aprendi a ver um outro mundo e entender melhor o nosso. Muda a ideia de relação de família, a noção de consumo, a relação com o meio ambiente, e a ideia da relação entre o indivíduo e a sociedade. A gente é um indivíduo e ao mesmo tempo um grupo. Os Guarani me ensinaram muito isso. Eles têm muito presente essa coisa da ética, da estética, e da poética. Depois fui trabalhar na área de educação especificamente. Fui 
percebendo, no contato com outros povos, a importância da sociodiversidade para pensar um futuro de país.

Fale um pouco sobre a ação e a política indigenista no Brasil. Quais principais diretrizes devem orientar a política indigenista no Brasil em benefício dos Povos Indígenas em sua visão. Por quê?

A primeira coisa chave para construir políticas públicas indigenistas é o respeito. Agente só respeita aquilo que conhece. Então, as políticas indigenistas demandam que se conheça cada um dos povos. Daí vem o respeito. E pautado pelo respeito, tem que vir o diálogo. Temos que entrar em diálogo com eles, conhecendo-os. Porque eles são obrigados a nos conhecer, mas nós não somos obrigados a conhecê-los. E na hora do diálogo, outra chave para pensar políticas indigenistas, é a língua. Para que haja um diálogo de fato, é muito importante que as categorias de pensamento dos povos indígenas sejam compreendidas por quem está fazendo o diálogo. A língua portuguesa restringe de maneira muito destrutiva as categorias de pensamento e de vida dos povos indígenas. Eu acho que agente deve, obrigatoriamente, aprender as línguas indígenas para pensar essas políticas.

Como compreende o papel do Estado em geral, e da Fundação Nacional do Índio, no contexto da relação com os indígenas e no plano da política indigenista no Brasil?

Ainda acredito, não só que o Estado tem o dever de estar presente, fazendo esse diálogo com conhecimento e respeito, mas que o Estado deveria se beneficiar dos povos indígenas. A Funai também deve estar presente e mais fortalecida na ponta. As Coordenações Regionais da Funai deveriam ser mais robustas. As equipes regionais ganhando bem, valorizadas, e a equipe de Brasília mais reduzida. Esse equilíbrio de 
servidores e serviços deveria ser alterado entre Brasília e Regionais. E esses órgãos deveriam se beneficiar, aprender com esses conhecimentos. O Brasil é melhor porque tem os povos indígenas. Eles não são problema; ao contrário. Agente tem essa sorte de ter esse enorme capital social, cultural, ambiental, espiritual dos povos indígenas. Eu ainda acredito que o Estado deve melhorar. Pode melhorar. Agente tem muito a aprimorar porque os espaços de participação, conselhos, comitês, em que os indígenas têm ou teriam participação no sentido de influenciar o Estado, estão muito ruins, precários. Funcionam em espaços-tempos completamente avessos à lógica dos povos indígenas. Mesmo os Comitês Regionais da Funai não funcionam a contento, porque os representantes indígenas não conseguem compreender e dar palpite sobre aquela burocracia. Então acho que agente tem muito a aprimorar.

Como indigenista, avalia que a existência e a atuação da Funai são importantes para os povos indígenas?

Acho que a Funai cumpre um papel absolutamente fundamental. Quem trabalha com indígenas, faz a ponte entre os povos indígenas e as políticas públicas, compreende que a Funai é quem minimamente conhece como cada povo indígena é, como as coisas funcionam, e conhece as pessoas em campo. Mesmo que outros órgãos trabalhem com políticas voltadas para os indígenas, quem mais conhece o tema é a Funai.

Que consequências uma eventual extinção da Funai poderia acarretar para os povos indígenas, em sua visão?

Não acho que a Funai deve ser extinta de maneira alguma. Teve um tempo no Brasil, de transição do final dos anos 1980 para os 1990, quando a Funai perde a competência da 
Educação Indígena, Saúde indígena, atividades produtivas, em que pensou-se nessa extinção. Mas esse tempo passou. E ao contrário, os indigenistas passaram a perceber que a Funai cumpria um papel fundamental de quem estava na ponta, de quem conhece, sabe como as coisas funcionam. Para além de toda parte territorial que ficou como atribuição da Funai, ela foi ocupando um outro espaço. Foi aí, nos anos 90 até começo dos anos 2000, que foi se dando uma transformação do órgão. Não é mais a instituição tutora, mãe, que dá aos índios, mas o órgão que detém a competência desse acúmulo de conhecimento sobre os povos indígenas, que os outros ministérios não têm.

\section{Como descreve sua experiência à frente da Funai?}

Eu gostei muito. Foi muito bom para mim o período que fiquei na Funai. Aprendi a conhecer outros povos indígenas que não conhecia. Como o pessoal do Xingu, do Nordeste, do Acre, etc... Foi um privilégio ter essa oportunidade. E todo o aprendizado de estar no governo. Por menos que tenhamos conseguido fazer, sinto que consegui falar muitas coisas em locais e em momentos importantes da nossa história. Gostei muito de conhecer o governo por dentro. Agora sinto que falo com muito mais conhecimento. Sabemos como funciona lá dentro, quais as dificuldades que existem.

Quais foram os maiores desafios, as situações ou questões mais difíceis durante sua gestão?

A maior frustração é você ter que tocar um violino sem corda, sem orquestra, sem uma caixa de ressonância no Governo. Você está sozinha. O maestro não conhece a pauta que você está tocando. O maior desafio é o desconhecimento. A maior dificuldade foi perceber e entender como a questão indígena e os povos indígenas são grandes desconhecidos dos fazedores, dos implementadores das políticas públicas. Não só dos 
Ministros, que estão numa posição mais política. Mas das equipes técnicas dos diferentes Ministérios, que tinham que atuar junto a essas políticas coordenadas pela Funai. Era muito difícil você explicar e tentar mostrar como é que são os povos indígenas, porque a gestão territorial e ambiental é tão importante, porque é difícil pensar em implementar a agricultura familiar do jeito que está pensada para os sem terra, a questão da documentação... todas as políticas públicas esbarram em questões que dizem respeito ao desconhecimento dos técnicos. Isso não é culpa dos técnicos, é que a nossa população não indígena é completamente ignorante dos índios, não teve oportunidade de aprender.

Quais as conquistas mais significativas do período de sua gestão, em sua opinião?

Eu acho que uma das conquistas daquela época foi fincar pé de que a Funai é importante. Foi um período que a Funai estava perdendo, digamos, prestígio dentro do Governo. E eu acho que com a minha gestão agente conseguiu dar uma cara nova para Funai. Não só no sentido de cara externa, mas uma cara e produtos de competência da Funai novos. Tem um respeito hoje. É bem diferente de como era quando a Funai era vista como um órgão completamente desprestigiado, e os técnicos da Funai eram vistos apenas como pessoas que falavam com os índios, sem know-how, sem técnica. Não sei se estou sendo meio fantasiosa, mas eu acho que essa conquista veio para ficar, no sentido de que, não só o governo, mas a opinião pública reconhece que a Funai tem uma expertise própria bem importante no que diz respeito a tudo, documentação, cesta básica, avaliação da política pública, terra. A minha gestão não virou isso. Já fazia parte da gestão do (ex-presidente) Márcio (Meira) essa ideia. Mas acho que agente conseguiu avançar. 
Por que e em que situação decidiu deixar a Presidência do órgão?

Tinha toda uma linha política do próprio Governo e da opinião pública que faz parte desse desconhecimento sobre o modo de vida dos indígenas e sobre a possibilidade de outros modelos de desenvolvimento. Ficou uma primazia de um modelo de desenvolvimento que o Governo estava pautando e bancando, e negociando politicamente com setores da sociedade brasileira, que são totalmente contrários às ideias que agente tinha junto com os povos indígenas, de futuro, de modelo de desenvolvimento, de melhoria de qualidade de vida. Então, acho que esse posto de Presidente da Funai era meio temporário, porque você tem que estar negociando essa visão. Participando de uma visão de desenvolvimento de governo, e ao mesmo tempo, do lado dos povos indígenas, e tentando fazer com que os indígenas sejam ouvidos e respeitados. Então eu percebi que tinha um tempo. E quando fui ficando doente, medindo o que dava para fazer, fui percebendo que o tempo era limitado.

Fale um pouco sobre o atual contexto, que envolve uma sériede ações anti-indígenas? Quais as maiores ameaças à sobrevivência e aos direitos dos povos indígenas na atualidade?

Cada vez mais temos que abrir espaços para que todos os setores da população no Brasil pensem sobre a questão dos povos indígenas, conheçam os povos indígenas, e para que esse modelo de desenvolvimento seja posto em discussão. Para que a gente possa refletir de maneira mais crítica. Hoje se dão alianças entre os povos indígenas e os coletivos de SP, por exemplo, que são muito interessantes. Isso é positivo. Então, acho que essas ameaças são expressões de setores que pensam um Brasil futuro de um jeito que a gente, junto com os povos indígenas e outros setores no Brasil, estamos tendo que dialogar e brigar e pensar outras maneiras de vivermos. 
Em que o cenário atual se assemelha ou se distingue do contexto pré 1988? Isso é; as ofensivas, as violações sofridas pelos indígenas hoje são muito diferentes daquelas de períodos históricos anteriores no Brasil?

No começo dos anos 1980 a gente passou uma fase assim também. Era a época de um movimento pró-emancipação dos indígenas. Esses fantasmas voltam. São fases. Que voltam por desconhecimento, preconceito. Agora tem a PEC (Proposta de Emenda à Constituição n⿳⺈ 215/2000, que transfere parte das atribuições relativas à demarcação de terras indígenas ao Poder Legislativo), mas os índios já estavam morrendo, sendo assassinados desde os anos 80. No Governo Lula, foram assassinados mais de 100 lideranças Kaiowá e a grande mídia não falava nada. Não consigo achar que hoje é pior. Claro, (o conjunto de ofensivas) está formalizado de um jeito que nós, que somos de um grupo social específico, no sentido de formação intelectual que faz a ponte com os indígenas, que estamos na academia, temos que ter um papel mais atuante do que tínhamos quando os Guarani Kaiowá estavam morrendo em 2000. Naquela situação, toda a reação se resumia à nota que os antropólogos da ABA (Associação Brasileira de Antropologia) soltavam. Então é um desafio para todo mundo que pensa o Brasil de um outro jeito.

Fale um pouco sobre as iniciativas que vêm sendo discutidas no Congresso Nacional (PEC 215 Proposta de Emenda à Constituição n 215/2000, que transfere parte das atribuições relativas à demarcação de terras indígenas ao Poder Legislativo; projetos de regulamentação do artigo 231 da Constituição Federal; Comissão Parlamentar de Inquérito para investigar os atos da Funai e do Incra), relacionadas diretamente com as garantias normativas estabelecidas em favor dos povos indigenas. 
O conflito está dado para além dessas iniciativas. Quem vivencia, por exemplo, a situação do Mato Grosso do Sul, ou do Maranhão, ou de Rondônia, ou Mato Grosso, sabe que o conflito está lá, está dado. Essas coisas que estão se concretizando no Congresso são expressões desses conflitos que estão acontecendo no campo há muito tempo. Já fazem parte da nossa história. A gente tem que participar mais. Fico muito irritada quando vejo muita gente criticando o Governo, o Congresso. E nós? Somos cidadãos. Então a responsabilidade é nossa, é de todo mundo, é compartilhada. Eu acredito nisso. E a responsabilidade de quem colocou aquele Congresso lá? Então, acho que a gente tem que cada vez mais botar a boca no trombone, falar, discutir... Agora, sou sempre pacifista. Acredito muito em conflitos mediados por diálogos, por vivências.

Qual a importância da Constituição Federal de 1988 para os povos indígenas?

É absolutamente importante a Constituição e o que a gente conquistou, os índios, seus parceiros, do campo em que eu me coloco, os cidadãos e o Brasil. Mas acho que é um tempo histórico que passa. Paraguai, Colômbia, por exemplo, tinham legislações muito mais avançadas. Enquanto discutíamos os nossos direitos constitucionais (nos anos 80), no Paraguai estava se batalhando por uma legislação de propriedade comunitária da terra. Tudo isso também corre risco de dar passos para trás. Temos que comemorar essa Constituição, mas também revisitá-la, e aprimorá-la, e acho que essa pode ser uma oportunidade.

A Constituição, o Direito do Estado, podem ser considerados instrumentos importantes na luta em defesa dos povos indígenas atualmente? Que outras ferramentas são indispensáveis nessa luta?

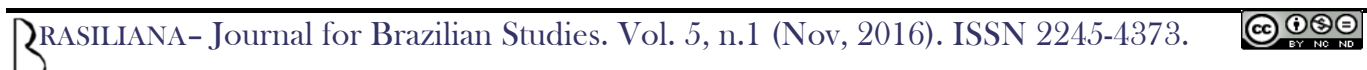


Para mim, a questão da judicialização dos processos de terras indígenas é uma das questões mais complicadas hoje. Mais que a PEC, que a CPI. Ela ocorre em ambientes muito fechados, em tempos incontroláveis. A gente devia conversar mais sobre isso. Fiquei muito chocada quando aprendi, já na Funai, que a maioria dos processos de demarcação estava judicializada. O Judiciário é um campo fundamental de luta hoje. É a grande floresta não explorada por nós, que está nos assombrando cada vez mais, e que cada vez mais a gente desconhece. A gente não valoriza o suficiente. Pessoal (Judiciário) fica 10 anos com um processo e a gente acha que isso é normal. Isso é uma loucura, porque são as pessoas que estão em jogo. Gerações de indígenas crescendo na beira das estradas porque os processos judiciais não andam. Porque tem um juiz que não tem tempo para julgar o processo ou não prioriza, e que muitas vezes não tem a menor ideia do que está acontecendo nas comunidades mesmo. E as regras da Justiça, todo o aparato legal, a jurisprudência, são espaços-tempo que temos que tomar como espaços-tempo de discussão, de argumentação, de diálogos. A apropriação desse instrumento com uma concepção pluricultural é muito importante. O Direito tem que ser aberto para a reflexão à luz da nova antropologia perspectivista, por exemplo. Quem pautou a PEC 215? Foi o Judiciário, a partir da discussão do processo de decisão sobre as condicionantes (da demarcação da Terra Indígena) Raposa (Serra do Sol).

Durante a Campanha Presidencial em 2014, a Presidenta Dilma assumiu com lideranças do Movimento Indígena uma série de compromissos de cumprimento dos direitos desses povos, garantindo a não alteração de dispositivos constitucionais. Afirmando contar com o apoio do segmento indígena para o enfrentamento conjunto dos desafios que se colocam, referiu-se à garantia do bem viver para todos os povos indígenas no Brasil. Acha que esses compromissos vêm sendo cumpridos, ou podem ainda ser cumpridos? 
Acho que a gente ainda tem muito a percorrer. Uma coisa é o que se diz em campanha, outra é o dia-a-dia. Como falei, as equipes que estão implementando as políticas públicas no Governo Federal,ainda desconhecem muito o Brasil nas suas regiões e os não indígenas nessas regiões, mas desconhecem também os povos indígenas. Obviamente que ninguém vai chegar nisso agora. Eu acredito que não é só o Governo o responsável por chegarmos onde se almeja, se sonha. Os próprios indígenas são coresponsáveis, as organizações indígenas, lá na base, nos conselhos. Eles estão aprendendo também. A gente consegue chegar sempre até onde nossa consciência coletiva chega. Não adianta só haver meia dúzia de pessoas com conhecimentos, pensarem que a PNGATI $^{1}$ vai consertar os males do mundo e que vai transformar o Brasil num país multiétnico. Precisamos de todo mundo, necessitamos que a população nesse país tenha uma consciência coletiva. Estamos caminhando, mas ainda com muita dificuldade. Acho que a Conferência (I Conferência de Política Indigenista realizada no ano de 2015) foi um passo importante. As gerações indígenas mais jovens estão ocupando espaços importantes com um pensamento diferente daquele dos anos 1980, 1990. Isso agente precisa compreender, respeitar.Estão ocupando espaços de participação, cargos no Executivo, com uma outra cabeça. Isso tudo é um processo dinâmico que ainda não sabemos onde vai chegar. É lógico que a gente gostaria que o Governo Federal desse muito mais importância aos povos indígenas. Eu gostaria muito, por exemplo, que os governantes federais tivessem tido experiências em comunidades indígenas, nas diferentes regiões do Brasil, que tivessem aprendido coisas por lá. Um dos serviços mais interessantes que os índios poderiam prestar seria deixar os

1

Política Nacional de Gestão Ambiental e Territorial das Terras Indígenas, instituída por meio do decreto governamental no 7747 de 05 de junho de 2012 
governantes federais fazerem um estágio de dois meses em aldeias. Isso poderia mudar tudo...

O que seria necessário, em sua opinião, para a reversão desse quadro de ameaças às vidas e culturas dos Povos Indígenas e violações de seus direitos?

Educação para mim é estratégico. A educação é revolucionária, como Paulo Freire sempre falava. Melhorar a formação das crianças no Brasil nas escolas não indígenas é uma das coisas principais para virar essa página de uma vez. Melhorar o conhecimento sobre o assunto. É absolutamente fundamental. 